\title{
Effect of aging on bioavailability of copper on the fluvo aquic soil
}

\author{
${ }^{1,2} \mathrm{G}$ Guo, ${ }^{1}$ T. Yuan, ${ }^{1}{ }^{*} \mathrm{~W}$. Wang, ${ }^{1} \mathrm{D} . \mathrm{Li},{ }^{2} \mathrm{~J}$. Wang \\ ${ }^{1}$ School of Environmental Science and Engineering, Shanghai Jiao Tong University, China \\ ${ }^{2}$ School of Life and Environmental Science, Shanghai Normal University, China
}

Received 1 July 2010; revised 13 November 2010; accepted 11 March 2011

\begin{abstract}
The bioavailability of copper in contaminated soils has received more attention due to the safety concern of food chain. The bioavailability of metals is determined by its fractions which are affected by the soil properties and its aging time. This paper focused on the aging effect on the bioavailability of copper added to the soil. The garden soil (fluvo aquic soil) was treated with $100 \mathrm{mg} / \mathrm{kg}$ and $1000 \mathrm{mg} / \mathrm{kg}$ of copper(II) sulfate and incubated for 14, $21,28,42,63,120,200,300$ and 400 days in the laboratory respectively. The sequential extraction procedure was used to characterize copper bioavailability in the soil. Meanwhile, the barley was cultured on the same soil incubated and its toxicity was assessed according to the guideline of International Organization for Standardization. The findings show that the exchangeable and carbonate-bound copper decreased with the aging time after addition of copper(II) sulfate to soil. Meanwhile, the percentages of Fe-Mn oxides- and organic-bound copper increased. The residual copper was changed little during the aging course. The copper fractions became stable in soils after 60 days. The kinetic equations showed that the Power function and the Elovich equation were well fitted to the experimental data, and the $\mathrm{r}^{2}$ values ranged from 0.840 to 0.982 and 0.741 to 0.975 , respectively. The barley test showed that the barley root length was more sensitive to reflect copper toxicity than the shoot biomass, and the exchangeable and carbonate-bound copper were significantly correlated with the barley root length.
\end{abstract}

Keywords: Aging effect; Bioavailability; Copper; Kinetics; Soil fractions

\section{INTRODUCTION}

In recent years, the impact of heavy metal on soil has been received a particular concern due to its persistency in soil and therefore its relativity to the security of food chain (Chojnacka et al., 2005; Kidd et al., 2007; Ayari et al., 2010). Among the metals, copper in contaminated soils has been received more attentions. Metal fractions in soil is influenced by the soil's physicochemical properties, such as soil $\mathrm{pH}$, clay, organic matter content and content, as well as longterm fixation or aging effects. These soil properties and processes largely determine metal fractions and further its bioavailability in soil environments (Oorts et al., 2006; Jalali et al., 2008; Li et al., 2009; Nouri et al., 2011).

The aging of metals in soils has been demonstrated to be a major factor in determining their availability (Tagami and Uchida 1998; Ma et al., 2006a; Ma et al., 2006b ). It has been found that the proportions of the

*Corresponding Author Email: whwang@sjtu.edu.cn Tel./Fax: +8621 54742823 most labile $\mathrm{Cu}$ fractions (exchangeable $\mathrm{Cu}$ ) were decreased with increasing incubation time, whereas those of $\mathrm{Cu}$ bound to crystalline and amorphous materials (residual $\mathrm{Cu}$ ) exhibited the opposite trend ( $\mathrm{Lu}$ et al., 2009). It has also been found that a timedependent decrease in total water extractable and bioavailable $\mathrm{Cu}$ during incubation at field capacity for up to 200 days in an in vitro assay and suggested that soil moisture and incubation time were the major effects factors on the bioavailability of copper in soil (Nouri, 1980; Petersen et al., 2004). The distribution of $\mathrm{Cu}$ fraction is a function of the $\mathrm{Cu}$ concentration added to the soil and the incubation time (Arias-Estévez et al., 2007). Although the long-term aging has been recognized as a key process in the risk assessment of metals in field soils, the process still needs more in detail information (Ma et al., 2006; Quazi et al., 2010).

The objective of this study was to examine the effects of aging on the fractionations and the dynamic bioavailability changes of $\mathrm{Cu}$ in fluvo aquic soils in 
order to assess the ecological risk in the $\mathrm{Cu}$ contaminated soils. The effectiveness of aging on bioavailability was assessed by $\mathrm{Cu}$ fractions and a plant test. To achieve this end, the aging experiment was carried out from March 2007 to May 2008 at the School of Environmental Science and Engineering, Shanghai Jiao Tong University.

\section{MATERIALS AND METHODS}

Soil collection and its physiochemical characterization

The soil samples (fluvo aquic soil) were collected from the top layer $(0-20 \mathrm{~cm})$ in a garden of Shanghai city. The values of $\mathrm{pH}$ were measured in a solution of $0.01 \mathrm{M} \mathrm{CaCl}_{2}$ (soil: solution =1:5). The Total organic carbon (TOC) in soils was calculated from the difference between total carbon and inorganic carbon (Oorts et al., 2006), which were measured by means of Multi N/C 3000 analyzer (Analytik Jena AG, Germany).

The Cation exchange capacity (CEC) was determined by the silver thiourea method at soil $\mathrm{pH}$ (Chhabra et al., 1975; Ammann et al., 2005). The texture was analyzed with the hydrometer method. The content of calcium carbonate was determined by treating each soil with $\mathrm{HCl}$ and measuring the liberated $\mathrm{CO}_{2}$. Total ambient $\mathrm{Cu}(\mathrm{T}-\mathrm{Cu})$ in the soils was digested with an aqua regia, and analyzed by ICP-AESÿIRIS Advantage/1000, TJA, USAÿ(McGrath and Cunliffe, 1985). Soil physiochemical properties were charactered in Table1. Results are presented as the average of three replicates. The recoveries of $\mathrm{Cu}$ in this study were $93 \%$

\section{Soil incubation course}

The soil was air-dried, sieved (mesh size, $4 \mathrm{~mm}$ ) and then spiked with $\mathrm{CuSO}_{4}$ solution at two concentrations of $100 \mathrm{mg} / \mathrm{kg}$ and $1000 \mathrm{mg} / \mathrm{kg}$, respectively. After thoroughly mixed, the soils were air-dried and sieved again through $4 \mathrm{~mm}$ mesh. Then the soils were incubated at room temperature. And two portion samples were taken at $14,21,28,42,63$, $120,200,300$ and 400 days, one for the detection of $\mathrm{Cu}$ content and its fractions, another for the bioavailability assessment below.

\section{Bioavailability of $\mathrm{Cu}$ in barley}

Two barley bioavailability assays were performed: one with a root elongation assay based on the guideline of International Organization for Standardization (ISO) 11269-1 (ISO, 1993), and another with a shoot biomass assay based on the guideline of ISO 11269-2 (ISO, 1995). Approximately $500 \mathrm{~g}$ soil was first mixed thoroughly with deionized water to make the soil grainy and then placed in a plastic pot. 10 seeds of barley were germinated in each plastic pot and irrigated to field capacity with deionized water. Three pots for each treatment were performed as the triplicates and kept in the incubator (SPX-250B-G) with a light intensity of 5000 lux for a duration of 16:8 light:dark photoperiod at the temperature of $15 \pm 2{ }^{\circ} \mathrm{C}$ and random relocation once a week. The soil moisture of every pot was maintained at $80 \%$ field capacity by the deionized water during the incubation course (Ginocchio et al., 2006). After 21 days, the plants were removed intact and their length of the longest root on each plant was recorded. The root lengths of each treatment were calculated from 30 plants in triplicate pots. Then the fresh plants were air-dried for bioavailability assessment in the laboratory at room temperature in order to record the shoot biomass and to determine $\mathrm{Cu}$ content. The same soils without $\mathrm{Cu}$ addition were used as controls. Results were expressed in percentage of effect compared to the control.

\section{Detection of $\mathrm{Cu}$ in soil and plant}

The soil and plant samples in triplication were digested with nitric acid individually and the $\mathrm{Cu}$ fractions in soils were extracted according to the process by Tessier et al. (1979). All the solutions above were detected by ICP-AES (IRIS Advantage/1000, TJA, USA) (Rooney et al., 2006). The sum of all extraction steps for each metal was 86.6-107.4\% compared with the total $\mathrm{Cu}$ contents in the same soil sample. Every digestion batch included a blank sample and a triplicate sample. The standard reference materials (reference

Table 1: Physiochemical properties of the soil

\begin{tabular}{lcccccc}
\hline Location & $\mathrm{pH} \mathrm{CaCl}_{2}(0.01 \mathrm{M})$ & $\mathrm{CaCO}_{3}(\%)$ & $\mathrm{TOC}(\mathrm{g} / \mathrm{kg})$ & $\mathrm{CEC}(\mathrm{cmol} / \mathrm{kg})$ & $\mathrm{Clay}(\%)$ & $\mathrm{T}-\mathrm{Cu}(\mathrm{mg} / \mathrm{kg})$ \\
\hline Shanghai & 7.01 & 2.90 & 8.87 & 16.91 & 17 & $23.86^{*}$ \\
\hline
\end{tabular}

* The value was lower than $30 \mathrm{mg} / \mathrm{kg}$ (WHO) 
material serial number GBW-07421; Center for National Standard Reference Materials of China. The content of $\mathrm{Cu}$ is $17 \mu \mathrm{g} / \mathrm{g}$ in the reference) was inserted to the analytical process for quality control.

\section{RESULTS AND DISCUSSION}

The profile of $\mathrm{Cu}$ fractions in soil during the aging course

During the aging course, the changes of $\mathrm{Cu}$ percentage in different fractions of the soils were shown in Fig. 1. Although the external $\mathrm{Cu}$ added to the soils were different, i.e. sample A with $100 \mathrm{mg} / \mathrm{kg}$ and sample $\mathrm{B}$ with $1000 \mathrm{mg} / \mathrm{kg}$, their curve figures of $\mathrm{Cu}$ fractions were similar. At the beginning of $\mathrm{CuSO}_{4}$ addition into soil, the percentage of exchangeable, carbonate-bound, Fe-Mn oxides-bound, organic-bound and residual fractions in two batches were $50 \%$ and $60 \%, 20 \%$ and $21 \%, 9 \%$ and $13 \%, 8 \%$ and $9 \%, 1 \%$ and $10 \%$ respectively. It was well known that the exchangeable
$\mathrm{Cu}$ with labile bound could be easily released into the soil solution and further be absorbed by plant, which might cause the hazard to the ecosystem and food chain. With the increase of the incubation time the exchangeable $\mathrm{Cu}$ was decreased sharply within the first 60 days after the $\mathrm{Cu}$ addition. Then the change became slowly and only $4 \%$ and $5 \%$ of exchangeable $\mathrm{Cu}$ was left in the two different soil samples at 400 days.

Similarly, the decreases in the carbonate-bound fraction were also observed during the incubation, but the variation was not as much as the former. It was remained in $6.8 \%$ and $15.3 \%$ respectively in the two soils at 400 days of incubation, which means carbonate fractions with a loosely bound could be changed with environmental conditions (Stone and Marsalek, 1996; Navas and Lindhorfer, 2003), (Fig. 1). In contrast to the fractions above, the proportions of $\mathrm{Cu}$ in the Fe-Mn oxides-bound fraction
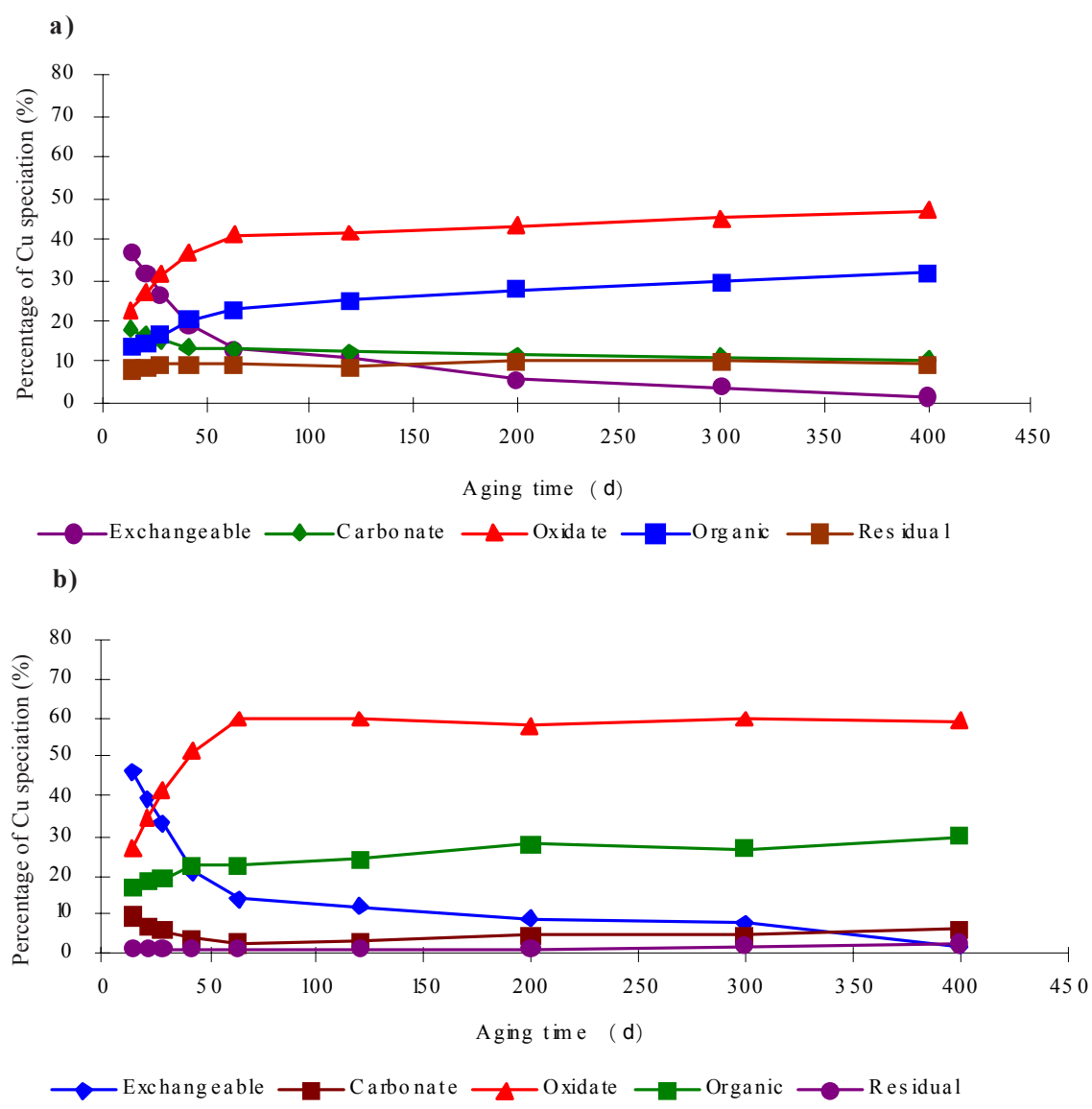

Fig 1: The variation of $\mathrm{Cu}$ percentage in different fractions of the soil during time course a) The external $\mathrm{Cu}$ addition was $100 \mathrm{mg} / \mathrm{kg}$ soil; b) The external $\mathrm{Cu}$ addition was $1000 \mathrm{mg} / \mathrm{kg}$ soil 
were increased sharply during the incubation in the first 60 days and then became smoothly. At 400 days of incubation it was reached in $44.7 \%$ and $59.2 \%$, respectively.

The proportions of $\mathrm{Cu}$ in the organic-bound fraction were increased slightly during the incubation but the variation was not significant as much as that in Fe-Mn oxides-bound fraction. It was reached in $26.5 \%$ and $30.1 \%$ respectively at the end of the incubation. Filgueiras et al. (2002) found that the metal fractions bound to Fe-Mn oxides- and to organic matter were relatively stable and not easily used by biological paths under normal soil conditions. The residual fraction changed less in this research. The variation rate was less than $1 \%$ and $3 \%$ in sample A and sample B respectively during the aging course. Residual fraction was often considered to be bound within the lattice of minerals and consequently could not be released into the environment (Balasoiu et al., 2001).

In summary, there were clear changes in the proportional distribution of $\mathrm{Cu}$ in the two soils during the incubation after $\mathrm{Cu}$ addition. The proportions of $\mathrm{Cu}$ associated with most weakly bound fractions (exchangeable and carbonate-bound fractions) tended to decrease, with corresponding increases in the other three more strongly binding fractions. The differences in the rates of redistribution are most probably due to the addition $\mathrm{Cu}$ into soil.

Results of the present investigation indicate that the metals could be adsorbed on the solid surface by relatively weak electrostatic interaction, and then the sorbed metal fractions may undergo a slow transformation into more stable fractions that were less susceptible to release back into solution and were not readily accessed even by the smallest of microorganisms and the tissues of higher organisms during the aging course (Alexander, 2000; Elzinga et al., 2006).

\section{The kinetics of Cu fractions turned over during aging course}

The kinetics of $\mathrm{Cu}$ turned over in different fractions during the aging course could be fitted by the following equations (Shirvani et al., 2007; Jalali and Khanlari, 2008):

Elovich equation: $q_{t}=a+b \ln t$

Power function $q_{t}=a t^{b}$

Parabolic diffusion $q_{t}=a+b t^{1 / 2}$

Where $q_{t}$ is $\mathrm{Cu}$ decreased or increased at time $t$, a and $b$ are constants, $t$ is time (d). The goodness of fit was evaluated based on coefficients of determination $\left(\mathrm{r}^{2}\right)$ and standard errors of estimate (SEE) calculated as follows:

$S E E=\left(\frac{\sum\left(q_{t}-q_{t}^{\prime}\right)^{2}}{n-2}\right)^{1 / 2}$

$\mathrm{q}_{\mathrm{t}}$ and $\mathrm{q}_{\mathrm{t}}$ are the measured and predicted $\mathrm{Cu}$ decreased or increased, respectively and $\mathrm{n}$ is the number of measurements. The experimental data in the study were matched with the three kinetic equations above and their fits were presented in Table 2.

The values of $\mathrm{r}^{2}$ were ranged from 0.840 to 0.982 with Power function (PO), from 0.741 to 0.975 with Elovich equation (EL) and from 0.596 to 0.949 with Parabolic diffusion equation (PA). The order of well fitting was $\mathrm{PO}>\mathrm{EL}>\mathrm{PA}$. This was accordance with the research of Xu et al. (2008), who observed that the copper and zinc in red soil, paddy soil and cinnamon

Table 2: The $\mathrm{r}^{2}$ and SEE of the models fit with the different $\mathrm{Cu}$ fractions a

\begin{tabular}{llcccccc}
\hline \multirow{2}{*}{ Soils } & & \multicolumn{2}{c}{ Elovich } & \multicolumn{2}{c}{ Power function } & \multicolumn{2}{c}{ Parabolic diffusion } \\
\hline \multirow{3}{*}{ A } & & $\mathrm{r}^{2}$ & SEE & $\mathrm{r}^{2}$ & SEE & $\mathrm{r}^{2}$ & SEE \\
\cline { 3 - 8 } & Exchangeble & 0.961 & 0.771 & 0.982 & 1.272 & 0.832 & 0.387 \\
& Carbonate & 0.933 & 0.208 & 0.960 & 1.307 & 0.749 & 0.142 \\
& Fe-Mn xides & 0.885 & 0.843 & 0.840 & 2.418 & 0.685 & 0.359 \\
& Organic & 0.975 & 0.298 & 0.944 & 0.881 & 0.808 & 0.164 \\
B & Exchangeble & 0.906 & 1.488 & 0.977 & 5.122 & 0.768 & 0.456 \\
& Carbonate & 0.877 & 0.226 & 0.941 & 2.619 & 0.786 & 0.597 \\
& Fe-Mn xides & 0.741 & 2.018 & 0.879 & 5.354 & 0.596 & 5.501 \\
& Organic & 0.958 & 0.299 & 0.950 & 0.781 & 0.949 & 0.799 \\
\hline
\end{tabular}

${ }^{a}$ The probability level $<0.05$ 
soil fitted better the $\mathrm{PO}$ and $\mathrm{El}\left(\mathrm{r}^{2}\right.$ were 0.8813 to 0.9359 and 0.8289 to 0.9085 ), whereas PA has less goodness of fit during the aging processes $\left(\mathrm{r}^{2}\right.$ were 0.5409 to 0.7385) (Xu et al., 2008). However, Jalali and Khanlari (2008) found that all three models used above were well fitted to experimental data and the parabolic equation is the best of the equations to describe the experimental data.

By means of the kinetic equation, the concentration of liable $\mathrm{Cu}$ in soil could be calculated and further assess the ecological risk.

\section{The bioavailability assessment of $\mathrm{Cu}$ during the aging course}

As the indicators of $\mathrm{Cu}$ bioavailability, the inhibition rate of barley Root length (RL) and shoot biomass in the soil A and B during aging course was shown in Fig. 2 and Fig. 3 respectively.

Compared to the control, the inhibition rate on barley root length ranged from $14.01 \%$ to $36.07 \%$ in incubation soil $\mathrm{A}$ and from $45.86 \%$ to $57.6 \%$ in incubation soil B respectively (Fig. 2). The trend of Cu bioavailability in the two treatments was declined with the aging time, but the bioavailability of $\mathrm{Cu}$ in soil $\mathrm{A}$ was lower than that in soil B. It was also observed that the inhibition rate of biomass ranged from $56.4 \%$ to $65.3 \%$ in incubation soil $A$ and from $70.1 \%$ to $74.6 \%$ in incubation soil B respectively (Fig. 3). However, the variation of the biomass in two treatments was not as obviously as the RL. It seemed that the indicator with RL was more sensitive than the indicator with shoot biomass. This could be attributed from the different mechanism of uptake by plant. A strong translocation

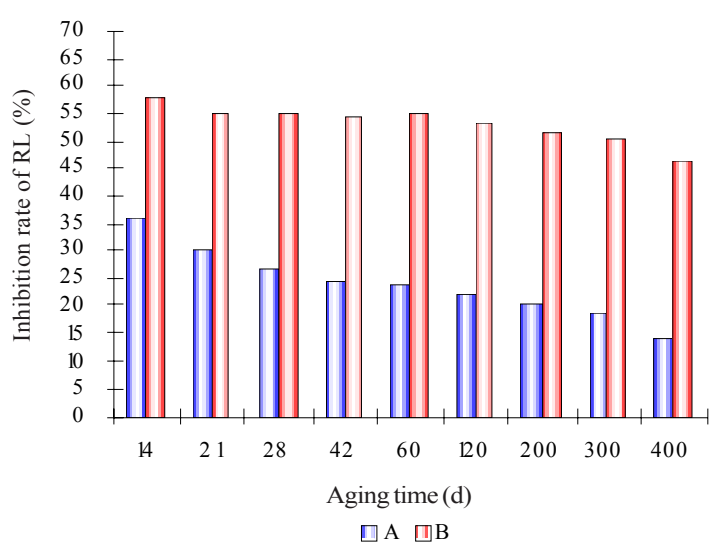

Fig. 2: Inhibition rate of barley RL aaduring the aging course barrier against $\mathrm{Cu}$ has been observed in many plant roots and higher levels of trace metals was accumulated mainly in the root, therefore, the root length is often used as a sensitive test for Cu toxicity (Schat and Ten Bookum, 1992; Nabulo et al., 2008).

The regressions between the $\mathrm{Cu}$ bioavailability (the barley RL test and the shoot biomass test) and the $\mathrm{Cu}$ fractions (exchangeable, carbonate-bound, Fe-Mn oxides-bound, organic-bound $\mathrm{Cu}$ ) were estimated to evaluate the $\mathrm{Cu}$ toxicity in the two treatments quantitively (Table 3 ).

The exchangeable and the carbonate-bound fractions in two soils were significantly correlated with the barley RL $\left(r^{2}=0.867, p<0.001 ; r^{2}=0.835, p=0.047\right.$ for incubation $A$ and $r^{2}=0.893, p=0.001 ; r^{2}=0.868, p=0.035$ for incubation $\mathrm{B}$, respectively). It proved that exchangeable and carbonate- bound $\mathrm{Cu}$ in soils are mainly bioavailable fractions, which might cause the hazard on plants ( Stone and Marsalek, 1996; Navas and Lindhorfer, 2003). The results also indicated that the exchangeable and carbonate-bound $\mathrm{Cu}$ have more effects on the barley root in the incubation $B$ than that in the incubation A. Because the bioavailable fractions of the former was higher than those of the latter.

The regression of $\mathrm{Cu}$ bound to the Fe-Mn oxidesand to the organic matter were less significantly correlated with the $\mathrm{RL}\left(\mathrm{r}^{2}=0.658, \mathrm{p}=0.061 ; \mathrm{r}^{2}=0.670, \mathrm{p}=\right.$ 0.124 for incubation $A$ and $r^{2}=0.771, p=0.109 ; r^{2}=0.724$, $\mathrm{p}=0.083$ for incubation $\mathrm{B}$, respectively), which indicated the less bioavailability of these two fractions.

The $\mathrm{r}^{2}$ test from the shoot biomass were generally lower than those test from the barley RL, indicating that the root growth was more directly affected by $\mathrm{Cu}$

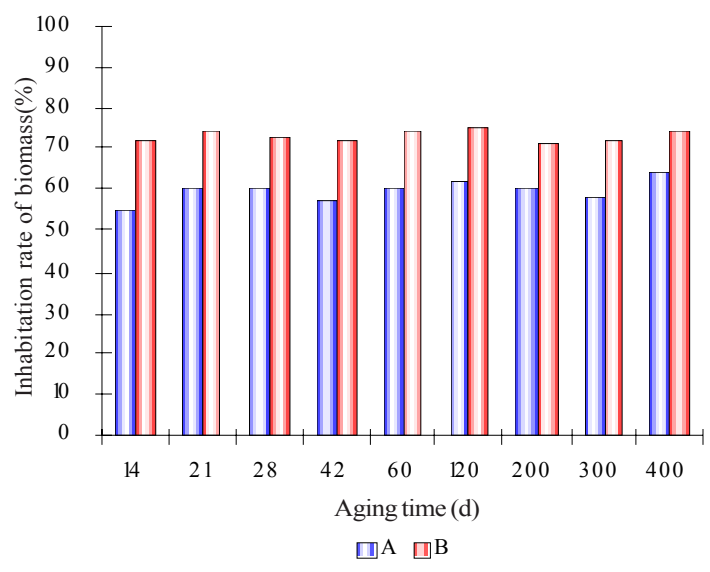

Fig. 3: Inhibition rate of biomass during the aging course 
Table 3: The regression of $\mathrm{Cu}$ bioavailability against $\mathrm{Cu}$ fractions

\begin{tabular}{|c|c|c|c|c|}
\hline Bioavailability & Variables & Regression equation & $r^{2}$ & $\mathrm{P}^{\mathrm{a}}$ \\
\hline \multicolumn{5}{|l|}{ RL } \\
\hline \multirow{4}{*}{ A } & Exch- $\mathrm{Cu}$ & $\log (\mathrm{RL})=1.21-0.16 \log (\mathrm{Exch}-\mathrm{Cu})$ & 0.867 & $<0.001$ \\
\hline & $\mathrm{Car}-\mathrm{Cu}$ & $\log (\mathrm{RL})=1.51-0.47 \log (\mathrm{Car}-\mathrm{Cu})$ & 0.835 & 0.047 \\
\hline & Oxid-Cu & $\log (R L)=0.38-0.53 \log ($ Oxid-Cu $)$ & 0.658 & 0.061 \\
\hline & Org-Cu & $\log (\mathrm{RL})=1.36-0.19 \log (\mathrm{Org}-\mathrm{Cu})$ & 0.670 & 0.124 \\
\hline \multirow{4}{*}{$\mathrm{B}$} & Exch- $\mathrm{Cu}$ & $\log (\mathrm{RL})=1.16-0.13 \log ($ Exch-Cu $)$ & 0.893 & $<0.001$ \\
\hline & $\mathrm{Car}-\mathrm{Cu}$ & $\log (\mathrm{RL})=1.00-0.08 \log (\mathrm{Car}-\mathrm{Cu})$ & 0.868 & 0.035 \\
\hline & Oxid-Cu & $\log (\mathrm{RL})=0.19-0.25 \log ($ Oxid-Cu $)$ & 0.771 & 0.109 \\
\hline & Org- $\mathrm{Cu}$ & $\log (R L)=0.68-0.43 \log (\mathrm{Org}-\mathrm{Cu})$ & 0.724 & 0.083 \\
\hline \multicolumn{5}{|l|}{ Biomass } \\
\hline \multirow{4}{*}{ A } & Exch- $\mathrm{Cu}$ & $\log ($ Biomass $)=1.75+0.41 \log ($ Exch-Cu $)$ & 0.638 & 0.071 \\
\hline & $\mathrm{Car}-\mathrm{Cu}$ & $\log ($ Biomass $)=1.60-0.52 \log (\mathrm{Car}-\mathrm{Cu})$ & 0.702 & 0.08 \\
\hline & Oxid- $\mathrm{Cu}$ & $\log ($ Biomass $)=0.57-0.7 \log ($ Oxid-Cu $)$ & 0.746 & 0.066 \\
\hline & Org-Cu & $\log ($ Biomass $)=1.43-0.82 \log ($ Org- $-\mathrm{Cu})$ & 0.591 & 0.094 \\
\hline \multirow{4}{*}{$\mathrm{B}$} & Exch- $\mathrm{Cu}$ & $\log ($ Biomass $)=0.26-1.33 \log ($ Exch $-\mathrm{Cu})$ & 0.694 & 0.141 \\
\hline & $\mathrm{Car}-\mathrm{Cu}$ & $\log ($ Biomass $)=0.86+0.15 \log (\mathrm{Car}-\mathrm{Cu})$ & 0.717 & 0.108 \\
\hline & Oxid-Cu & $\log ($ Biomass $)=2.65+0.72 \log ($ Oxid-Cu $)$ & 0.68 & 0.077 \\
\hline & Org-Cu & $\log ($ Biomass $)=1.02+0.58 \log ($ Org $-\mathrm{Cu})$ & 0.673 & 0.082 \\
\hline
\end{tabular}

${ }^{a}$ Significance level ( $p$ ) of the independent variables

toxicity than the shoot biomass and the former was more sensitive than the latter. Although sensitivity difference between the two tests was observed, the fractions affected the bioavailability of $\mathrm{Cu}$ to the plant in the similar way (Rooney et al., 2007).

\section{CONCLUSION}

In recent years, the metal fractionations are often recognized as an important parameter to assess metal toxicity in soil. The results above confirmed the positive correlations between $\mathrm{Cu}$ fractions and its toxicity to the plant.

$\mathrm{Cu}$ contents were significantly decreased in exchangeable and the carbonate-bound with the increased time, while the Fe-Mn oxides- and the organic-bound $\mathrm{Cu}$ showed the opposite trend. The results indicated that the $\mathrm{Cu}$ fractions were varied and their toxicity became less during the aging course.

The aging kinetics can be well fitted with the PO and $\mathrm{El}\left(\mathrm{r}^{2}=0.840-0.982 ; \mathrm{r}^{2}=0.741-0.975\right)$, which indicated that the aging of added $\mathrm{Cu}$ was a slow process. The easily extractable $\mathrm{Cu}$ fraction was transformed or transferred from active forms slowly into more stable forms, mostly into the Fe-Mn oxides- and the organic bound $\mathrm{Cu}$ which were less available.
The relationship of $\mathrm{Cu}$ fractions and their barley bioavailability indicted that the exchangeable and carbonate-bound $\mathrm{Cu}$ were the main fractions available to the plant, and its toxicity decreased with time. The other fractions were more stable and difficult to be uptaken by the plant.

In summary, $\mathrm{Cu}$ contents in the fractions of exchangeable and carbonate-bound, as well as in total and the aging duration could be as the main factors to assess the ecological risk of soil, especially the soil heavily polluted from an accidential event.

\section{ACKNOWLEDGEMENTS}

The authors are grateful for the financial support from the Key Lab of City Agriculture (South), Ministry of Agriculture, China (09UA004) and from the International Copper Association.

\section{REFERENCES}

Alexander, M., (2000). Ageing, Bioavailability and Overestimation of Risk from Environmental Pollutants. Environ. Sci. Tech., 34 (20), 4259- 4265 (7 pages).

Ammann, L. ; Bergaya, F.; Lagaly, G., (2005) . Determination of the cation exchange capacity of clays with copper complexes revisited. Clay Minerals, 40 (4), 441-453 (13 pages). 
Arias-Estévez, M.; Nóvoa-Muñoz, J. C.; Pateiro, M.; LópezPeriago, E., ( 2007). Influence of aging on copper fractionation in an acid soil. Soil Sci., 172 (3), 225-232 (8 pages).

Ayari, F.; Hamdi, H.; Jedidi, N.; Gharbi, N.; Kossai, R., (2010). Heavy metal distribution in soil and wheat plants in municipal solid waste compost-amended plots. Int. J. Environ. Sci. Tech., 7 (3), 465-472 (8 pages).

Balasoiu, C. F.; Zagury, G. J.; Deschênes, L., (2001). Partitioning and speciation of chromium, copper, and arsenic in CCA-contaminated soils: influence of soil composition. Sci. Total Environ., 280 (1-3), 239-255 (17 pages).

Chhabra, R.; Pleysier, J.; Cremers, A., (1975). The measurement of the cation exchange capacity and exchangeable cation in soils: A new method. Proceedings International Clay Conference, Mexico City, Mexico, 439449 (11 pages).

Chojnacka, K.; Chojnacki, A.; Góecka, H.; Góecki, H., (2005). Bioavailability of heavy metals from polluted soils to plants. Sci. Total Environ., 337 (1-3), 175-182 (8 pages).

Elzinga, E. J.; Rouff, A. A.; Reeder, R. J., (2006). The longterm fate of $\mathrm{Cu}^{2+}, \mathrm{Zn}^{2+}$, and $\mathrm{Pb}^{2+}$ adsorption complexes at the calcite surface: An X-ray absorption spectroscopy study. Geochim. Cosmochim. Ac., 70 (11), 2715-2725 (11 pages).

Filgueiras, A. V.; Lavilla, I.; Bendicho, C., (2002). Chemical sequential extraction for metal partitioning in environmental solid samples. J. Environ. Monitor., 4 (6), 823-857 (35 pages).

Ginocchio, R.; Sánchez, P.; de la Fuente, L. M.; Camus, I.; Bustamante, E. S. Y.; Urrestarazu, P.; Torres, J. C.; Rodriguez, P. H., (2006). Agricultural soils spiked with copper mine wastes and copper concentrate: Implications for copper bioavailability and bioaccumulation. Environ. Toxicol. Chem., 25 (3), 712-718 (7 pages).

International Organization for Standardization, (1993). Soil quality-Determination of the effects of pollutants on soil flora-Part 1: Method for the measurement of inhibition of root growth. Geneva, Switzerland.

International Organization for Standardization, (1995). Soil quality-Determination of the effects of pollutants on soil flora-Part 2: Effects of chemicals on the emergence and growth of higher plants. Geneva, Switzerland.

Jalali, M.; Khanlari, Z. V., (2008). Effect of aging process on the fractionation of heavy metals in some calcareous soils of Iran. Geoderma, 143 (1-2), 26-40 (15 pages).

Kidd, P. S.; Domínguez-Rodríguez, M. J.; Díez, J.; Monterroso, C., (2007). Bioavailability and plant accumulation of heavy metals and phosphorus in agricultural soils amended by long-term application of sewage sludge. Chemosphere, 66 (8), 1458-1467 (10 pages).

Li, H. F.; Gray, C.; Mico, C.; Zhao, F. J.; McGrath, S. P., (2009). Phytotoxicity and bioavailability of cobalt to plants in a range of soils. Chemosphere, 75 (7), 979-986 (8 pages)

Lu, A. X.; Zhang, S. H.; Qin, X. Y.; Wu, W. Y.; Liu, H. L., (2009). Aging effect on the mobility and bioavailability of copper in soil. J. Environ. Sci., 21 (2),173-178 (6 pages).
Ma, Y. B.; Lombi, E.; Oliver, I. W.; Nolan, A. L.; McLaughlin, M. J., (2006a). Long-term aging of copper added to soils. Environ. Sci. Tech., 40 (20), 6310-6317 (8 pages).

Ma, Y. B.; Lombi, E.; Nolan, A. L.; McLaughlin, M. J., (2006b). Short-term natural attenuation of copper in soils: Effects of time, temperature, and soil characteristics. Environ. Toxicol. Chem., 25 (3), 652-658 (7 pages).

McGrath, S. P.; Cunliffe, C. H., (1985). A simplified method for the extraction of the metals $\mathrm{Fe}, \mathrm{Zn}, \mathrm{Cu}, \mathrm{Ni}, \mathrm{Cd}, \mathrm{Pb}, \mathrm{Cr}$, $\mathrm{Co}$, and $\mathrm{Mn}$ from soils and sewage sludges. J. Sci. Food Agr., 36 (9), 794-798 (5 pages).

Nabulo, G.; Oryem Origa, H.; Nasinyama, G. W.; Cole, D., (2008). Assessment of $\mathrm{Zn}, \mathrm{Cu}, \mathrm{Pb}$ and $\mathrm{Ni}$ contamination in wetland soils and plants in the Lake Victoria basin. Int. J. Environ. Sci. Tech., 5 (1), 65-74 (10 pages).

Navas, A.; Lindhorfer, H., (2003). Geochemical speciation of heavy metals in semiarid soils of the central Ebro Valley (Spain). Environ. Int., 29 (1), 61-68 (8 pages).

Nouri, J., (1980). Heavy metals in sewage sludge, soils amended with sludge and their uptake by crop plants. Ph.D. Thesis, University of London, London, UK.

Nouri, J.; Lorestani, B.; Yousefi, N.; Khorasani, N.; Hasani, A. H.; Seif, S.; Cheraghi, M., (2011). Phytoremediation potential of native plants grown in the vicinity of Ahangaran lead-zinc mine (Hamedan, Iran). Environ. Earth Sci., 62 (3), 639-644 (6 pages).

Oorts, K.; Gesquiere, U.; Swinnen, K.; Smolders, E., (2006). Soil properties affecting the toxicity of $\mathrm{CuCl}_{2}$ and $\mathrm{NiCl}_{2}$ for soil microbial processes in freshly spiked soils. Environ. Toxicol. Chem., 25 (3), 836-844 (9 pages).

Petersen, T. A.; Hansen, H. C. B.; Nybroe, O., (2004). Time and moisture effects on total and bioavailable copper in soil water extracts. J. Environ. Qual., 33 (2), 505-512 (8 pages ).

Quazi, S.; Sarkar, D.; Datta, R., (2010). Effect of soil aging on arsenic fractionation and bioaccessibility in inorganic arsenical pesticide contaminated soils. Appl. Geochem., 25 (9), 1422-1430 (8 pages).

Rooney, C. P.; Zhao, F. J.; Mcgrath, S. P., (2006). Soil factors controlling the expression of copper toxicity to plants in a wide range of European soils. Environ. Toxicol. Chem., 25 (3), 726-732 (7 pages).

Rooney, C. P.; Zhao, F. J.; Mcgrath, S. P., (2007). Phytotoxicity of nickel in a range of European soils: Influence of soil properties, Ni solubility and speciation. Environ. Poll., 145 (2), 596-605 (10 pages).

Schat, H.; Ten Bookum, W. M., (1992). Genetic control of copper tolerance in Silene vulgaris. Heredity, 68, 219-229 (11 pages).

Shirvani, M.; Shariatmadari, H.; Kalbasi, M., (2007). Kinetics of cadmium desorption from fibrous silicate clay minerals:Influence of organic ligands and aging. Appl. Clay Sci., 37 (1-2), 175-184 (10 pages).

Stone, M.; Marsalek, J., (1996). Trace metal composition and speciation in street sediment: Sault Ste. Marie, Canada. Water Air Soil Poll., 87 (1-4), 149-169 (21 pages).

Tagami, K.; Uchida, S., (1998). Aging effect on bioavailability of $\mathrm{Mn}, \mathrm{Co}, \mathrm{Zn}$ and Tc in Japanese agricultural soils under waterlogged conditions. Geoderma, 84 (1-3), 3-13 (11 pages).

Tessier, A.; Campbell, P. G.; Blsson, M., (1979). Sequential 
extraction procedure for the speciation of particulate trace metals. J. Analys. Chem., 51 (7), 844-851 (8 pages).

Xu, M. G.; Wang, B. Q.; Zhou, S. W.; Li, S. Q.; Chen, M. M.;
Duan, G. L., (2008). Aging characteristics of copper and zinc added to typical soils of China. Environ. Sci., 29 (11), 3213-3218 (6 pages).

AUTHOR (S) BIOSKETCHES

Guo, G. Y., Ph.D. Candidate, School of Environmental Science and Engineering, Shanghai Jiao Tong University and School of Life and Environmental Science, Shanghai Normal University, China. Email: guangyongcn@163.com

Yuan, T., Ph.D., Associate Professor, School of Environmental Science and Engineering, Shanghai Jiao Tong University, China. Email: taoyuan@sjtu.edu.cn

Wang, W. H., Ph.D., Professor, School of Environmental Science and Engineering, Shanghai Jiao Tong University, China.

Email: whwang@sjtu.edu.cn

Li, D., Ph.D. Candidate, School of Environmental Science and Engineering, Shanghai Jiao Tong University, China.

Email:danli456@126.com

Wang, J., School of Life and Environmental Science, Shanghai Normal University, China. Email: shnuwj@shnu.edu.cn

How to cite this article: (Harvard style)

Guo, G. Y.; Yuan, T.; Wang, W. H.; Li, D.; Wang, J., (2011). Effect of aging on bioavailability of copper on the fluvo aquic soil. Int. J. Environ. Sci. Tech., 8 (4), 715-722. 